\title{
TEMPERATURE AND PORE PRESSURE DISTRIBUTION IN A CONCRETE SLAB DURING THE MICROWAVE DECONTAMINATION PROCESS
}

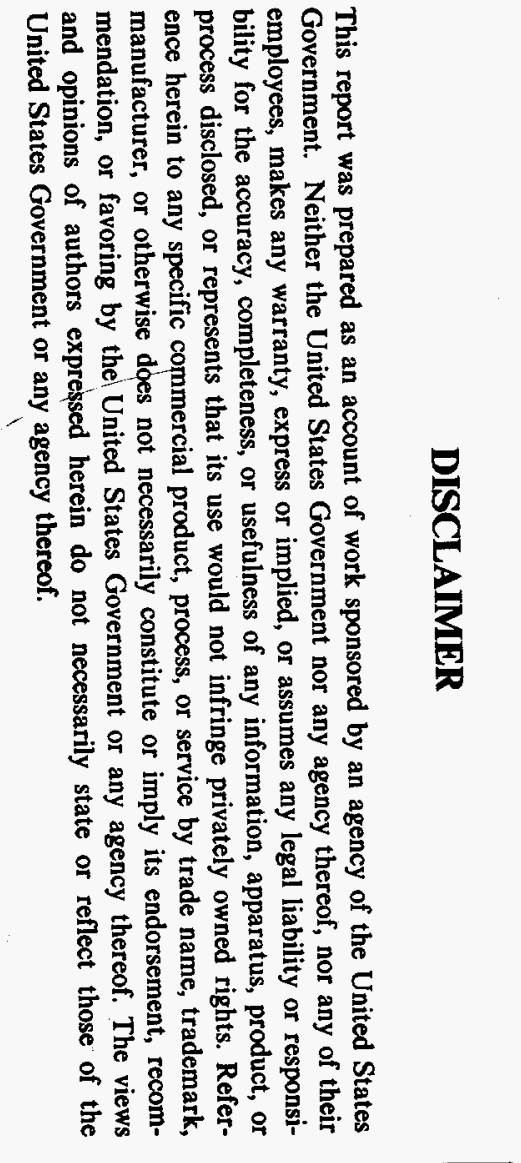

\author{
W. Li \\ M. A. Ebadian \\ Florida International University \\ Department of Mechanical Engineering, University Park \\ Miami, FL USA
}

T. L. White

Fusion Energy Division

R. G. Grubb

D. Foster, Jr.

Chemical Technology Division

Oak Ridge National Laboratory

P. O. Box 2009

Oak Ridge, TN 37831

10th Int. Heat Transfer Conf.

Brighton, England

August 14-18, 1994

Managed by Martin Marietta Energy Systems, Inc.for the U. S. Department of Energy under contract DE-AC05-84OR21400 
5. Li, W., Ebadian, M. A., White, T. L., Grubb, R. G., and Foster, D. "Temperature and Pore Pressure Distribution in a Concrete Slab During the Microwave Decontamination Process"

10th Int. Heat Transfer Conf., Brighton, England, August 14-18, 1994. 


\section{DISCLAIMER}

Portions of this document may be illegible in electronic image products. Images are produced from the best available original document. 


\title{
TEMPERATURE AND PORE PRESSURE DISTRIBUTION IN A CONCRETE SLAB DURING THE MICROWAVE DECONTAMINATION PROCESS
}

\author{
W. L and M. A. Ebadian" \\ Department of Mechanical Engineering \\ Florida international University, Miami, Florida, USA \\ T. L White ${ }^{+}$R. G. Grubb ${ }^{++}$and D. Foater ${ }^{++}$ \\ Fusion Energy Division \\ ${ }^{++}$Chemical Technology Division \\ Oak Ridge National Laboratory, Oak Ridge, Tennessee, USA
}

\begin{abstract}
As an application of microwave engincering, the new technology of concrete decontamination and decommissioning using microwave enersy has been recently developed. The temperature and pore pressure within the concrete are studied theoretically in this paper. The heat and man transfer within the porow concrete, coupled with temperature dependent dielectric property are investigated. The effects of microwave frequency (I), microwave power intensity $\left(Q_{Q, m e}\right)$, concrete porcaity $(b)$ on the temperature and pore preseure distributions and their variations are fulty discused. The effects of the variation of complex dielectric permittivity $\left(c^{\circ}\right)$ and preaentation $o$ different ateel reinforcements are aleo illuntrated.
\end{abstract}

\section{INTRODUCTION}

The use of microweve as a source of thermal energy is growing rapidly. The food induatry is the largeat consumer of microwave energy. Some succeaculul application are for the thawing of frozen meat, cooking bucon, and drying pasts. Microwaves are also widety used in the vulcanization of rubber (Copeon, 1975) and ceramic processing for drying and sintering (Bruce, 1988). Microwave technology is also employed in the drying of paper, forest products and textiles. More recently, microwave energy bas been applied to the decontamination of concrete. Several groupe in Japan, Yasunaka et al. (1987), in Europe, Hills (1989), and in the United States, White (1992), Li et al. (1993a), hrve begun developing new processes that use microwave energy for thermally treating radionctive wastea.

To model the trancient remperature distributions, the dissipated eloctric enerby is deduced by solving Maxwell's equations and is then incorporated as a source term in the transient energy equation. In several computational studie of microwave heating, the heat diesipation within foods has been modeled by Lambert's bw, in which the microwave power is attenuated exponentialty as a function of the distance of penetration into the sample (Data, 1990). Lamberi's law is valid for semi-infinite samples and has been used to predict temperature profilea during microwave heating (Wei et al. 1985). Ayappa et al. (1990) shomed that Lambert's law fails for samples thinner than three timea the characteriatic penetration depth of the microwave. Li et al. (1993) illuatrated a standing wave solution of the electromagnetic field for a multi-layer concrete alab in which a steel reinforcement layer was also considered. The assumption of consunt dielectric and thermal properties results in a linear probtem, decoupling the wave propagation from the accompanying heat transfer.

\footnotetext{
-Aulbor to whom all corrapondence should be addressed.
}

A recently mecoured by Ebadina and L (1992), the dieloctric propertices of coscrete are aho very enenitive to temperature. Therefore, the moalinear eloctromngnetic field must be coupled with the heat tnukfer procesa. To describe the dynamic phenomena cocurring in beated porous materink, We et al. (1985) derived equations for the different materials hxing a simple model of microwave beating scooxding to Lambert's inm.

In the current paper, the tempenture-dependent dielectric properties within the porous concrete are considered. The concrete dielectric propertie meneured by Ebedinn and $L$ i (1992) were employed. Based on porous concrete model with temperaturedependent dieloctric propertien, the efiloct of microwave frequency (f) on the temperature and pore preaure diutributions in discused. The effocts of coscrete poroity $(\$)$ on the modimum temperature and preasure are enmined. The diffenese between constunt and iempenture-dependent dielectric propery modek in aleo illustrated. Finally, the effect of presence of different stoel reinforcements on the temperature and premure dietributionen in aloo investigated.

\section{ELECTROMAGNETIC FIELD}

The concentration of ferromenetic material in concrete is negligible. Hence, the value of concrete permeability $\left(\mu_{\infty}\right)$ can be aseumed to be equal to the value of the air $\left(\mu_{2}\right)$, which is a constant not influeaced by temperature and frequency. The measurement of the variation of complex concrete dieloctric permittivity with tempera. ture has been conducted by Ebadian and Li (1992), and is employed in the curreas analyain.

\subsection{Maxwell's Equations}

During the decontamination procese, the front surface of a concrete alab $(z-0)$ is directly exposed to the microwave source, and the atcel reinforcement meah in located at a distance $\left(L_{3}\right)$ from the front suriace of the coscrete slab with a wal length (L), Fig. 1. The steel reinforcement within the concrete in treated as an intinite thin

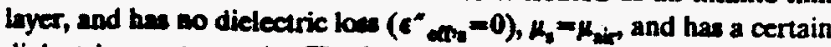
dielectric constant, $e^{\prime}$. The layer thictneas $(\delta)$ is very small and is totally neglocted in the beat and man tranafer. The fraction of refloction caued by the seed reinforcement $(\beta)$ is ausumed to be equal to a fraction of the croas-ectional ares of the concrete taken up by the sted meah (Li al al, 1993b). The concrete alab is furtber divided into $\mathrm{N}$ aubdivition. It is anumed that the concrete dielectric permittivity, $"\left(a^{\prime}-\mathrm{j} c^{\prime \prime}-\mathrm{d}\right)$, is uniform in each small subdivision, and in a function of the local temperature and the microwave froquency only. 


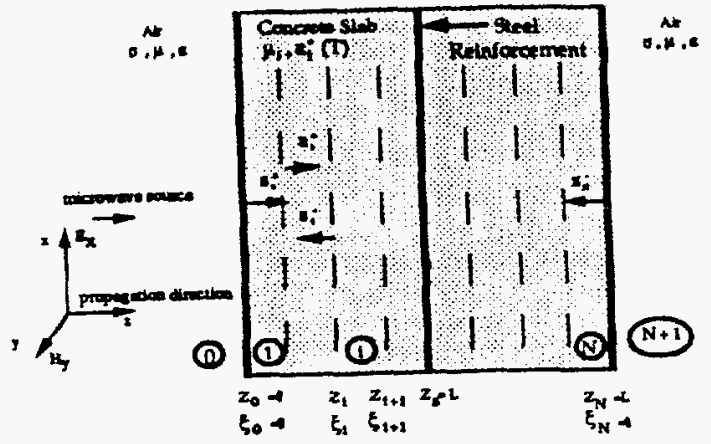

Fig. 1. Geometry of the concrete slab.

The governing equation for the electromagnetic fields in the $i$-th ( $i=0, \ldots, N+1)$ subdivision can be simplified as follows for the time harmonic plane microwave (Johnk, 1988):

$$
\begin{aligned}
& \frac{d E_{z}^{\prime}}{d x}-j \omega \omega H_{j}^{\prime} \\
& \frac{d H_{j}^{\prime}}{d z}-j \omega \varepsilon_{1}^{\prime} E_{2}^{\prime} .
\end{aligned}
$$

with the general solution, as:

$$
\begin{gathered}
E_{2}^{1}-E_{0}\left(E_{1}^{*} e^{-y_{1} z}+E_{1}^{-} e^{k_{2} z}\right) \\
H_{3}^{1}-\frac{E_{0}}{\eta_{1}}\left(E_{1}^{*} e^{-y_{2}}-E_{1}^{-} e^{t_{2} z}\right),
\end{gathered}
$$

in which

$$
z_{i}-j \omega \sqrt{\mu_{1} \epsilon_{i}^{*}} \text { ad } \eta_{1}-\sqrt{\mu_{1} / c_{i}^{*}} \text {. }
$$

where $E_{2}$ and $H_{y}$ are the electric and magnetic field potential, and $\mu_{i}$ and $c_{i}$ are the magnetic permeability and complex dielectric permittivity at the i-th division of the concrete, respectively. $\mathrm{E}_{\mathrm{j}}^{+}$and $\mathrm{E}_{\mathrm{j}}^{-}$are the unknown constants to be determined by the boundary conditions.

\subsection{Presence of the Steel Reinforcement}

When the infinitely thin reinforcement layer is located between sand $(a+1)$-th division, the energy reflection ratio, $\left|r_{3}\left(z_{2}\right)\right|^{2}$ has the following relation as, $L$ i et al. (1993b):

$$
\left.\left|\Gamma_{b}\left(z_{a}\right) p^{2}=\right| \frac{z_{1}-\eta_{1}^{\prime}}{z_{b}+\eta_{1}^{\prime}}\right|^{2}-\beta+(1-\beta)\left|\frac{z_{1}-\eta_{0}}{z_{3}+\eta_{0}}\right|^{2}
$$

where

$$
\Gamma_{1}=\frac{E_{1}^{-}}{E_{1}^{*}} e^{2 r_{1} z} \text { and } Z_{1}(z)=\frac{E_{1}^{i}}{K_{j}^{\prime}}-\eta_{1} \frac{1+\Gamma_{1}(z)}{1-\Gamma_{i}(z)} \text {. }
$$

All $E_{i}^{+}$and $E_{i}^{*}$ can be solved as $E_{0}^{+}=1$ and $E_{N+1}=0$.

\subsection{Microwave Power Dissipation}

The microwave power dissipation per unit volume is evaluated by:

$$
Q_{\text {mom }}^{i}=\frac{1}{2}\left(\omega \epsilon^{*}\right)\left|E_{x}\right|^{2} \text {. }
$$

It should be noted that the time averaged microwave power dissipation $\left(Q_{d, v e}^{\prime}\right)$ in the $i$-th subdivision is proportional to the imaginary part of the concrete complex dielectric permittivity $\left(\epsilon_{\text {eff }}^{*}\right)$ and the square of the norm of the complex electric potential $\left(\mathrm{E}_{x}\right)$, while both are strongly dependent on the temperature.

\section{TEMPERATURE AND PRESSURE}

Concrete is bacically a minture of cement and aggregate, both of which are porous. In addition, the concrete as a whote contains voids caused by incomplete compaction and cement bleeding. These voids may occupy from a fraction up to $20 \%$ of the whole volume of the concrete. Acoording to studies of the properties of concrete, as summarized by Neville (1981), the hydro-permeability of concrete is of the order, $7 \times 10^{-16} \mathrm{~m} / \mathrm{h}$, and the total surface area per unit of concrete volume is of the order, $4 \times 10^{8} \mathrm{~m}^{-1}$. In the concrete decontamination and docommistioning procen, the concrete apalling-off time is on the order of one minute. Therefore, movement of liquid, vapor, and air through the concrete is very alow. In the meantime, all phese within the concrete have a sufficiently large area to achieve equilibrium. Thus, it is reaconable to aesume that the local thermal equilibrium between all phasen (liquid, vapor, air, and the solid concrete matrix) is schieved instantaneourly.

\subsection{Governing Equations}

By conservation of mase, momentum, and energy in a porous medium, the governing equations of mass, momentum, and energy for the solid (0), liquid (1), vapor (2), and air (3) phases can be derived by using a volume (local) average lechnique [ct. Kaviany (1991)]:

Mas Comervation:

$$
\begin{gathered}
\phi \frac{\partial}{\partial t}\left(S_{1} p_{1}\right)+\Delta m=0 \\
\frac{\partial}{\partial t}\left[\left(1-S_{1}\right) p_{2}\right]-\Delta m=0 \\
\frac{\partial}{\partial t}\left[\left(1-S_{1}\right) p_{1}\right]=0
\end{gathered}
$$

Momentum Conservation:

$$
V_{1}=0, \quad 1=1,2,3,
$$

Energy Conservallon:

$$
\begin{aligned}
& \left(\rho C_{p}\right)_{0} \frac{\partial T}{\partial t}-\frac{\partial}{\partial z}\left(k_{-} \frac{\partial T}{\partial z}\right) \\
& +Q_{\Delta m o x}(T, z)-\Delta m \Delta h_{t}+\frac{\partial P_{1}}{\partial t},
\end{aligned}
$$

where

$$
\begin{aligned}
& \left(\rho c_{p b}=(1-\phi) p_{0} c_{p o}+\phi \sum_{i=1}^{3} s_{1} p_{1} c_{p l}\right. \\
& k_{2}=(1-\phi) k_{0}+\phi \sum_{i=1}^{3} s_{1} k_{1} \\
& s_{2}-s_{3}-1-s_{1} \text {. }
\end{aligned}
$$

Since $(1-)_{\rho} C_{p, 0}$ is dominant in $\left(\rho C_{p}\right)_{0}$, the variations resulting from the changes of $S_{1}$ and $p_{1}$ are insignificant. Therefore, the initial value of $\left(\rho C_{p}\right)_{0}$ is used in the calculation. Similar to $\left(\rho C_{p}\right)_{0}$ the initial value of $k_{\text {et }}$ is also used during the calculation.

Constltuthe State Equation:

Without considering the capillary preseure, the pressures have the following relation among three phases within the concrele:

$$
P-P_{1}-P_{2}+P_{3} \text {. }
$$

Although the hydro-permeability is very low, it might also be initially assumed that the vapor pressure $\left(\mathrm{P}_{2}\right)$ within the concrete is a function 
of the relative humidity around the concrete, which has the following relationship:

$$
P_{2}=P_{-}=
$$

where $\omega$ is the relative humidity around the concrete. For simplicity, saturated vapor $(\square=1)$ was used in the analyais. The residual water continuousty evaporates in the concrete when subjected to microwave heating. A fraction of the vapor phase is then almost dominant in the air-vapor mixture. Therefore, it is aseumed that the vapor pressure equals the saturation pressure of the vapor, i.e., $P_{2}=P_{\text {sax }}(D)$ throughout the entire process.

Precisely, the governing equations have four differential equations with three state equations and two pressure relations, which are nonlinear parabolic partial differential equations. It is estimated that the maximum value of $\mathrm{dP}_{1} / \mathrm{dT}$ is onty $1.7 \%$ of the value of $\left(\rho \mathrm{C}_{\mathrm{p}}\right)_{0}$ within the temperature range of 25 to $250^{\circ} \mathrm{C}$. Therefore, it is quite reasonable to neglect the term $\left(\partial P_{1} / \partial t\right)$.

\subsection{Initial and Boundary Conditions}

Knowing the initial condition of all densities $\left(\mathrm{p}_{\mathrm{i}}\right)$, the liquid volume saturation $\left(S_{1}\right)$, and temperature $(T)$ are required to solve the governing equations. The initial conditions are:

$$
\begin{aligned}
& P_{1}-p_{1,0}, p_{2}-p_{2,0}, p_{3}-p_{3,0}, S_{1}=S_{4,0}, \\
& T-T_{0} \text { and } P_{1}-P_{4,} \text { at } 1=0,
\end{aligned}
$$

where $P_{10}$ is the atmospheric pressure $(101.3 \mathrm{kPa})$. All initial conditions should also satisfy the state equations.

Assuming constant wall temperatures are specified at both the front and back surfaces of the concrete, one can then clarify the following boundary conditions:

$$
\mathbf{T}=\mathbf{T}_{\mathbf{*}}, \mathbf{z}=0, \mathrm{~L}
$$
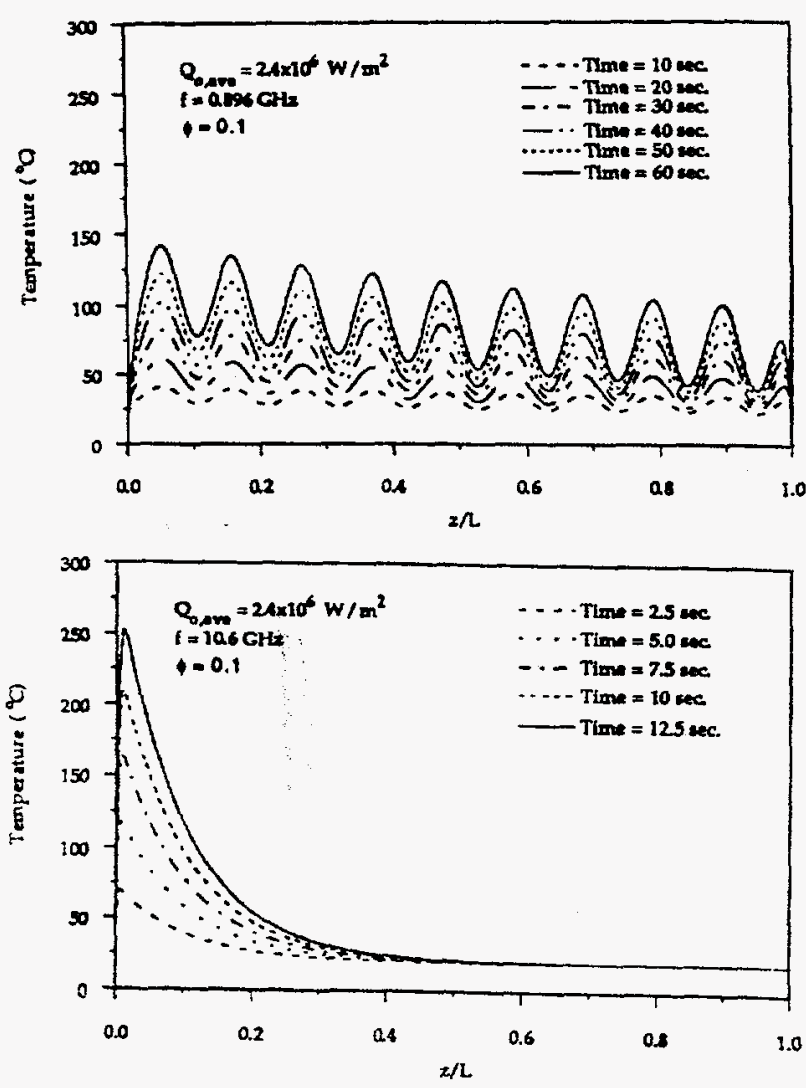

\section{RESULTS AND DISCUSSION}

In this section, the results of variations of the temperature distribution within $\& 0.6 \mathrm{~m}$ thick concrete slab are anatyzed. The comporition and the thernal properties of the concrete used in the analyin are listed in Table 1 . In the present discussion, four commonly ued frequencies, $0.896,2.45,10.6$, and $18.0 \mathrm{GHiz}$ are utilized.

TABLE 1

Values of the Ordinary Concrete Propertles

\begin{tabular}{|c|c|c|c|}
\hline$\rho\left[\mathrm{kg} / \mathrm{m}^{3}\right]$ & $\mathrm{C}_{p}[3 / \mathrm{kg} . \mathrm{K}]$ & $\mathrm{k}[\mathrm{W} / \mathrm{m} . \mathrm{K}]$ & $\sigma_{q}[\mathrm{Mpa}]$ \\
\hline 2,300 & 650 & 0.87 & $3.5-4.0$ \\
\hline
\end{tabular}

\subsection{Efrect of Frequency (I)}

For a certain power intentity $\left(Q_{Q, w e}=2.4 \times 10^{6} \mathrm{~W} / \mathrm{m}^{2}\right)$, temperature and preasure distributions for four microwave frequencies $(0.896$, 2.45, 10.6 and 18.0 GHiz) are plotied in Figs. 2 and 3. Figures 2 (a) and (b) show the temperature ditribution and its variation for frequencies of $0.896 \mathrm{GHz}$ and $2.45 \mathrm{GHz}$. The peaks of the temperature distribution decay slowly along the wave propagation direction (z). As seen in Figs. 2 (c) and (d), only one peak appears on the temperature distribution for the $f=10.6 \mathrm{GHz}$ or higher. Figure 3 shown the anme behevior for the pressure and its variation. Since pore pressure is not a linear function of temperature, the pressure distribution decaye more abruptly than the temperature does. It is demonstrated in Fig. 3 that for $\mathrm{f}=10.6 \mathrm{GHz}$ or higher, the pressure at a position deeper than $0.15 \mathrm{~m}(z / \mathrm{L}=0.2)$ does not change too much compared to the initial preseure $(0.1013 \mathrm{MPa})$.
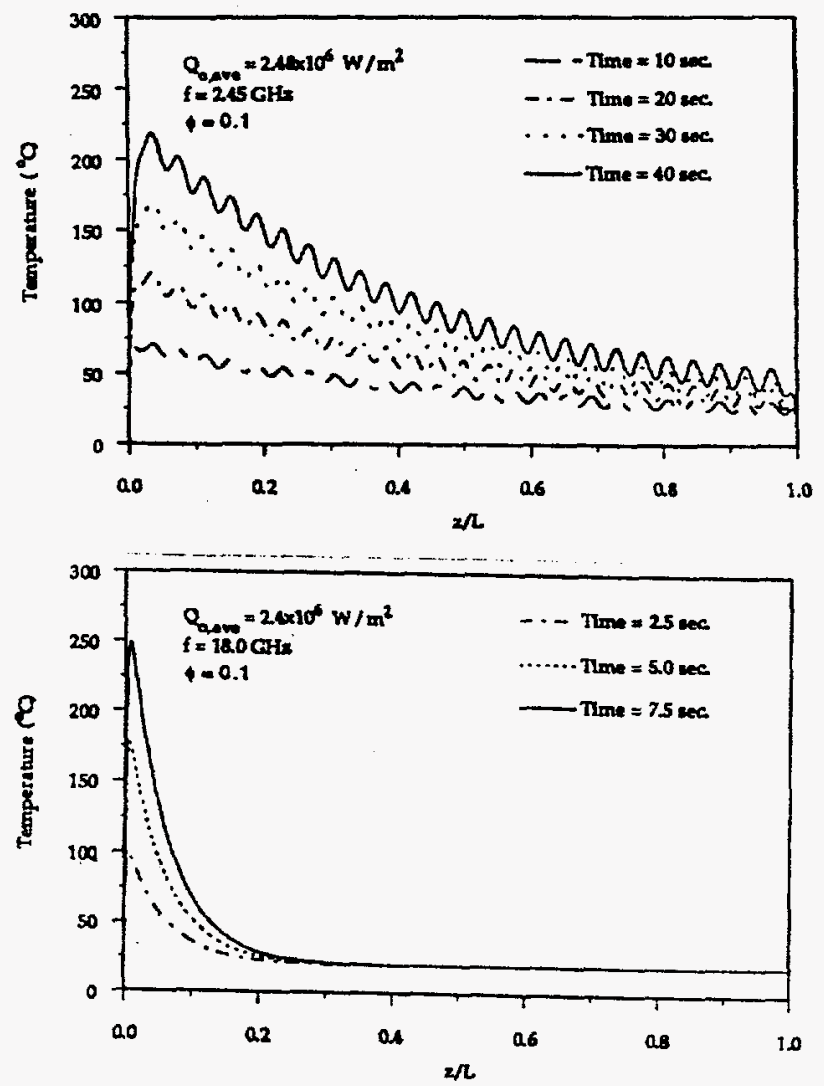

Fig. 2 Variations of temperature distribution within the concrete stab for $\phi=0.1$ and $Q_{0 \text { ave }}=2.4 \times 10^{\circ} \mathrm{W} / \mathrm{m}^{2}$. (a) For $\mathrm{f}=0.896 \mathrm{GHz}$; (b) For $\mathrm{f}=2.45 \mathrm{GHz}$; (c) For $\mathrm{f}=10.6 \mathrm{GHz} ;$ (d) For $\mathrm{f}=8.0 \mathrm{GHz}$. 

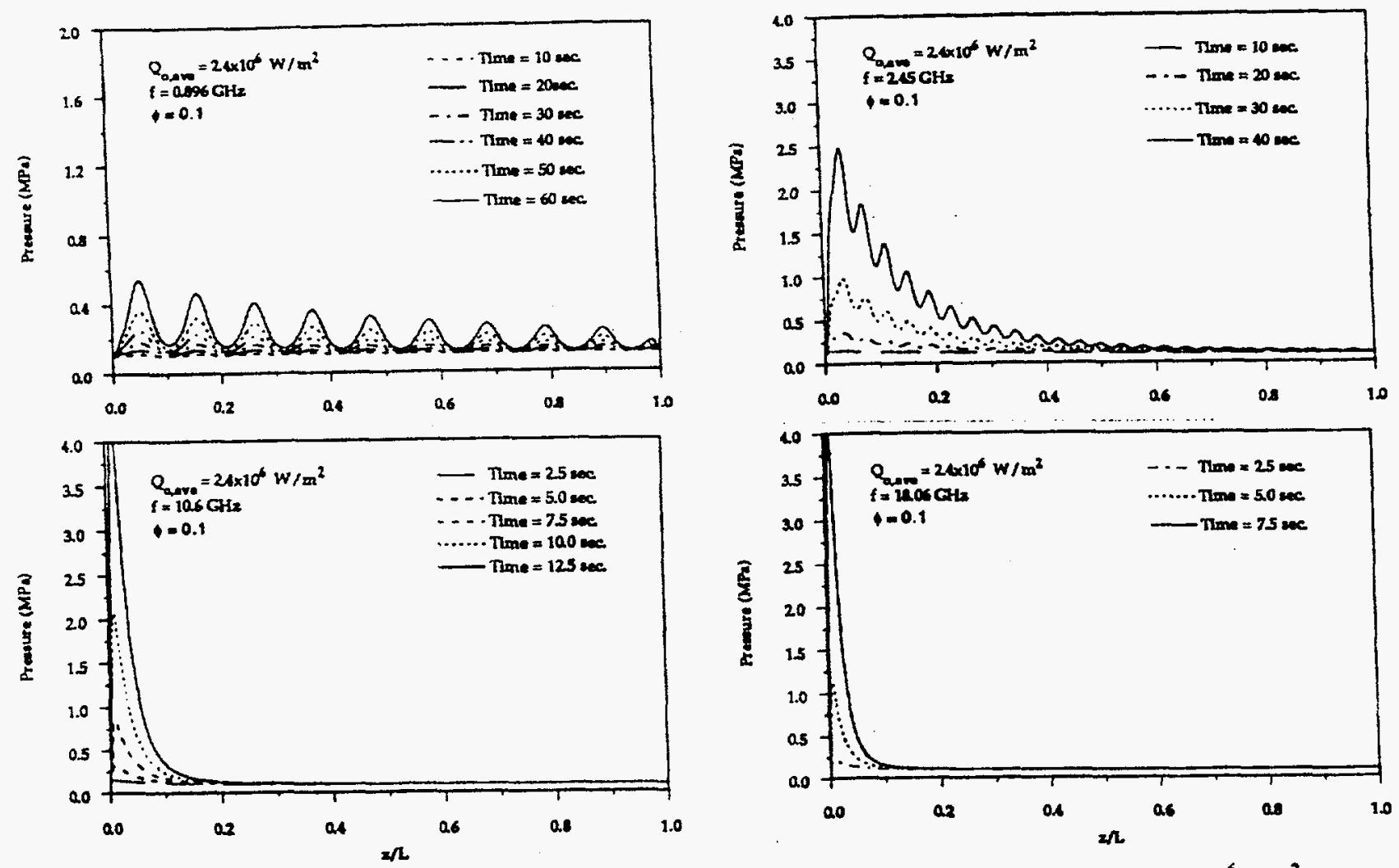

Fig. 3 Variations of pore pressure distribution within the concrete slab for $\$=0.1$ and $Q_{Q m a n}=2.4 \times 10^{6} \mathrm{~W} / \mathrm{m}^{2}$.

(a) For $f=0.896 \mathrm{GHz} ;$ (b) For $\mathrm{f}=2.45 \mathrm{GHz}$; (c) For $\mathrm{f}=10.6 \mathrm{GHz}$; (d) For $\mathrm{f}=8.0 \mathrm{GHz}$

\subsection{Efrect of Concrete Porosity (ф)}

The effects of concrete porctity ( $\phi$ ) on the maximum temperature and pressure with different heating times are listed in Table 2 . In this table, $\phi=0.0$ refers to the solid concrete conduction model results calculated by $L$ et al. (1993a). Only the maximum temperature is given in this column since pore pressure is not defined within the solid concrete. It is seen from the table that as porosity increases, the maximum temperature decreases slightly. For a higher porosity value, there is more void space and more liquid phase within the concrete. Generally, during the heating process, more liquid will be evaporated, which requires more energy to raise the temperature of the solid. Table 2 shows that as the concrete porosity varies from 0.0 to 0.3 , the maximum temperature and pressure barely change for the same heating time and temperature range of 20 to $250^{\circ} \mathrm{C}$, which corresponds to the steam pressure $P_{1} \approx_{0}$, since only a small amount of microwave power dissipation is used to evaporate the liquid within the concrete.

\subsection{Effect of Dielectric Permittivity $\left(\epsilon^{*}\right)$}

The temperature and pore pressure distributions and their variations within the concrete are dependent on the microwave power dissipation. In Figs. 4, Case 1 representa the temperature dependent dielectric permittivity while Case 2 presents the dielectric permittivity, which assumes that the dielectric permittivity equals to the value measured at $25^{\circ} \mathrm{C}$

At low Irequenciea ( $<2.45 \mathrm{GHz}$ ), as the dielectric permittivity varies with temperature, the temperature distribution due to the variation of " (Case 1) is significantly higher than that of constant - (Case 2). The variation of the power dissipation due to the variation of the dielectric permittivity initiates a greater rise in temperature, Fig. 4(a). For the higher microwave frequencies, the microwave penetration becomes smaller regardless of how the dielectric permittivity changes. Except for the energy reflected from the front surface of the concrete, all microwave energy is absorbed in a distance leas than $10 \mathrm{~cm}$ from the froat surface for $f=10.6 \mathrm{GHz}$ and leas than $5 \mathrm{~cm}$ for $f=18.0 \mathrm{GHz}$, Fig. 4(b). Corresponding to the temperature distributions, the pore pressure distributions for low frequencies ( $\leq 2.45 \mathrm{GHz}$ ) ascend to a higher level, Figs. 4(c). When

TABLE 2

Effect of Porosity $(\phi)$ on $T_{-}\left({ }^{\circ} \mathrm{C}\right)$ and $P=(M P$ e $)$ at $Q_{0, e}=2.4 \times 10^{\circ} \mathrm{W} / \mathrm{m}^{2}$

\begin{tabular}{|c|c|c|c|c|}
\hline \multicolumn{5}{|c|}{$I=2.45 \mathrm{GHz}$} \\
\hline$t(s)$ & $T_{\max }$ & $T_{\operatorname{mix}} P_{\operatorname{mix}}$ & $T_{\max } \int_{\max }$ & $\mathrm{T}_{\max } \mathrm{P}_{\max }$ \\
\hline 5.0 & 45.81 & $45.81 / 0.12$ & $45.80 / 0.12$ & $45.80 / 0.12$ \\
\hline 10.0 & 71.23 & 71.210 .16 & $71.19 / 0.17$ & $71.15 / 0.17$ \\
\hline 15.0 & 96.35 & 96.3110 .22 & 96.2710 .22 & 96.2110 .22 \\
\hline 20.0 & 121.23 & 121.180 .36 & $121.07 / 0.36$ & 120.920 .36 \\
\hline 25.0 & 145.91 & $145.75 / 0.59$ & $145.60 / 0.59$ & $145.45 / 0.59$ \\
\hline 30.0 & 170.42 & $170.16 / 0.98$ & $169.90 / 0.97$ & $169.64 / 0.97$ \\
\hline 35.0 & 194.80 & $194.37 / 1.59$ & $193.95 / 1.57$ & $193.53 / 1.56$ \\
\hline 40.0 & 219.05 & $218.38 / 2.48$ & $217.73 / 2.45$ & $217.09 / 2.42$ \\
\hline 45.0 & 243.18 & $242.16 \sqrt{3.74}$ & $241.17 / 3.68$ & $240.21 / 3.62$ \\
\hline \multicolumn{5}{|c|}{$f=10.6 \mathrm{GHz}$} \\
\hline 5.0 & 117.74 & $117.67 / 0.33$ & $117.60 / 0.33$ & $117.53 / 0.33$ \\
\hline 10.0 & 209.38 & $208.84 / 2.08$ & $208.31 / 2.06$ & $207.80 / 2.04$ \\
\hline 15.0 & 297.50 & $294.83 / 8.35$ & $292.42 / 8.07$ & 290.2277 .83 \\
\hline
\end{tabular}



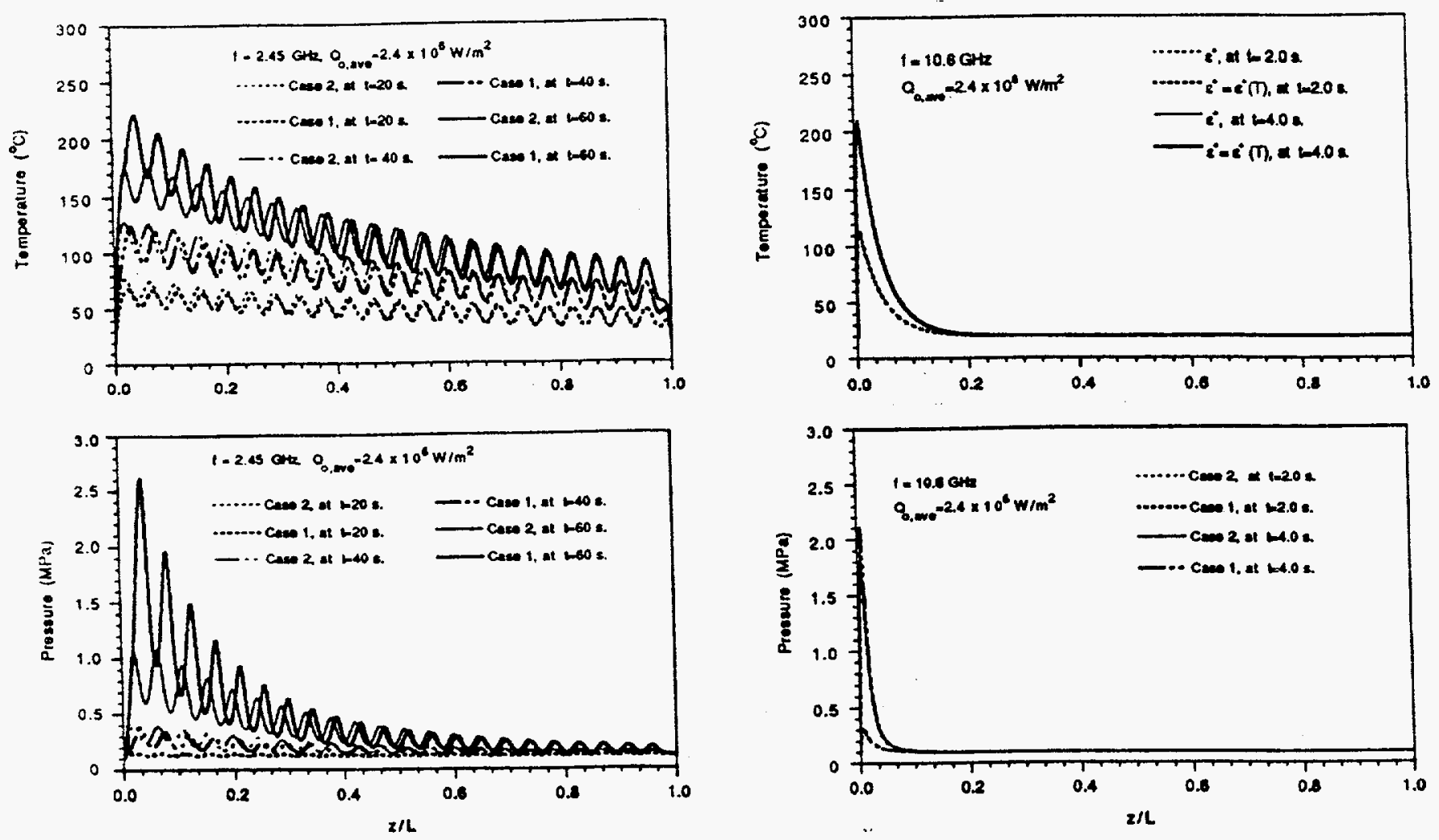

Fig. 4 Effect of temperature-dependent dielectric permittivity $\left(c^{\circ}\right)$ on temperature and pressure distributions for $=0.1$ and $Q_{0 . m e}=2.4 \times 10^{6} \mathrm{~W} / \mathrm{m}^{2}$. (a) Temperature, $f=2.45 \mathrm{GHz}$; (b) Temperature, $f=10.6 \mathrm{GHz}$; (c) Pressure, $f=2.45 \mathrm{GHz}$; (d) Pressure, $\mathrm{f}=10.6 \mathrm{GHz}$
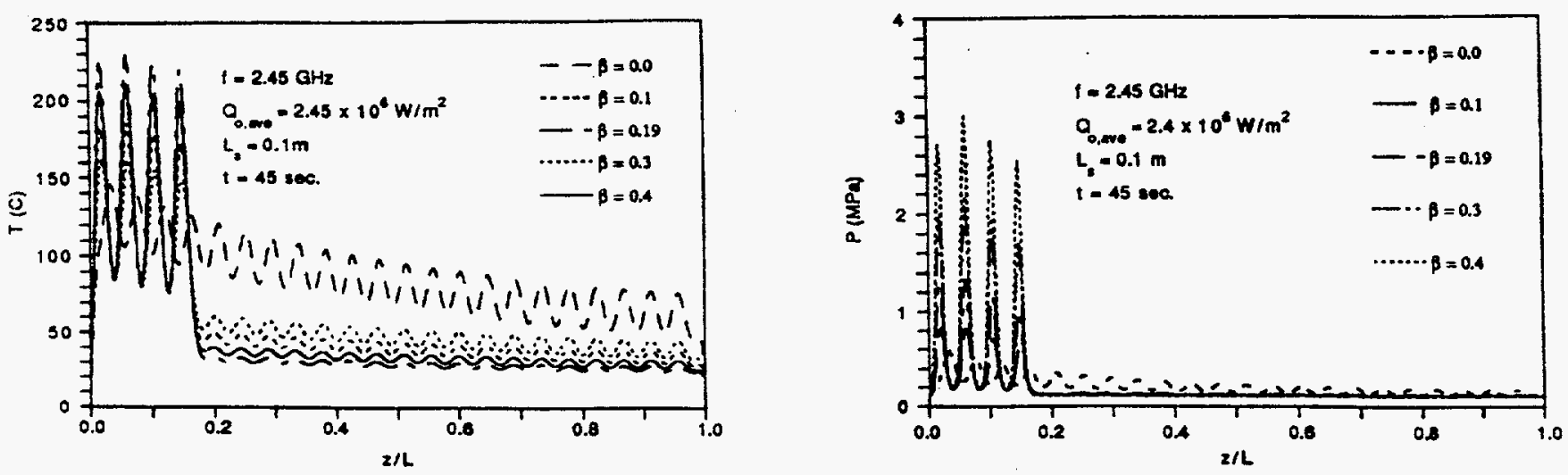

Fig. 5 Variation of the temperature and pressure distributions with and without the theel reinforcemeat bocated at $L_{\mathrm{z}}=0.1 \mathrm{~m}$ for different values of $A$ when $f=2.45 \mathrm{GHz}$ and $Q_{Q, m}=2.4 \times 10^{6} \mathrm{~W} / \mathrm{m}^{2}$. (a) Temperature at $t=45 \mathrm{sec}$; (b) Presaure distribution at $t=45$ sec.

the heating time increasca, the pressures for Case 1 become greater

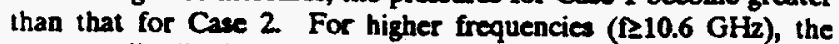
pressure distributions for both cases are almost identical, since the temperatures do not differ significantly, Fig. 4(d).

\subsection{Presentation of Steel Reinforcement}

The temperature distribution for $\mathrm{f}=2.45 \mathrm{GHz}, \mathrm{Q}_{\mathrm{ave}}=2.4 \times 10^{6}$ $W / \mathrm{m}^{2}, L_{3}=0.1 \mathrm{~m}$ and different values of $\beta$ at $t=45 \mathrm{sec}$ is plotted in Fig. $5(a)$. The corresponding pressure distribution is plotted in Fig. $S(b)$. Without steel reinforcement $(\beta=0)$, the temperature oscillates almost uniformly along the propagation direction. When different reinforcements are presented, the temperature and pressure oscillations become more and more evident as the value of $\beta$ increases. This indicates that with the presence of the reinforcement, the spalling-off time $\left(t_{1}\right)$ decreases as the value of $\beta$ increases. In addition to 2 riee in the maximum temperature, the locations of this maximum temperature also shif deeper into the concrete. The deeper maximum temperature will cause more concrete to be

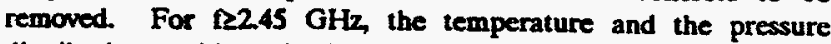
distributions, with and without steel reinforcements, are almost identical since the microwave penetration distance becomes shorter.

\section{CONCLUDING REMARKS}

A one-dimensional heat and mass transfer model coupled with temperature dependent dielectric property is developed in the current analysis. The microwave frequency $(\mathfrak{l})$, concrete porosity $(\phi)$ and 
different steel reinforcement are all considered. The following conclusions are made based on the results and discussion.

1. For the microwave frequency lower than $2.45 \mathrm{GHz}(\mathrm{f} \leq 2.45$ GHZ), the temperature and pore pressure distributione display the wavy behavior. The peak temperature and pressure decay slowty along the wave propagation direction, while for the micro-

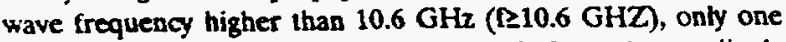
sharp peak of temperature and pressure is formed accordingly during the microwave heating process.

2. The effect of concrete porosity ( $\phi$ ) ranging from 0.0 to 0.3 can be neglected for the microwave power intensity from $6.0 \times 10^{5}$ to $6.0 \times 10^{6} \mathrm{~W} / \mathrm{m}^{2}$.

3. As $\varepsilon^{*}$ increase with temperature, the temperature and pressure distributions for a low frequency ( $[<2.45 \mathrm{GHz}$ ) change vitally. The effect of the variation of the concrete dielectric properties with temperature should be considered for a low frequency (f $<2.45 \mathrm{GHz}$ ).

4. When the reinforcement is present, the maximum temperature and pressure $\left(T_{\max }\right.$ and $\left.P_{\operatorname{mar}}\right)$ rise significantly as the value of $\beta$ increases. The concrete spalling-off time $\left(t_{3}\right)$ steadily decreases as the value of $\beta$ increases for a microwave frequency of 2.45 $\mathrm{GHz}$. For a microwave frequency of $10.6 \mathrm{GHz}$ or higher, the concrete spalling-off time $\left(t_{\mathrm{L}}\right)$ is nearly constant for $L_{t}=0.1 \mathrm{~m}$.

\section{ACKNOWLEDGMENT}

The resulu presented in this paper were obtained in the course of research sponsored by the Department of Energy under Subcontract No. 19X-SK164V

\section{REFERENCES}

Ayappa, K G., Davis, H. T., Davis, E. A and Gordon, J., 1990 Analysis of Microweve Heating of Materials With TemperatureDependent Propertice, AJChE J., vol. 37, pp. 313-322.

Bruce, R. W., 1988, New frontiers in the use of microwave encrgy: power and metrology, Microwave Processing of Materials, Ed., Sutton, W. H., Brooke, M. H. and Chabinsiky, I. J., Materials Research Society, Pittsburgh, Pennsylvania.

Copson, D. A, 1975, Microwave Heating, 2nd ed., AVI Publishing, Westpon, Connecticut.

Dala, A K, 1990, Heal and Mase Transfer in Microwave Processing of Food, Chem Eng Prog, vol. 6, p.47.

Ebadian, M. A. and Li, W., 1992, A Theoretical/Experimental Investigation of the Decontamination of a Radioactively Contaminatod Concrete Surface Using Microwave Technology, Final Report, DOE Project (DE-ACOS-840R2140), 1992.

Hills, D. L, 1989, The Removal of Concrete Layers from Biological Shields by Microwne, EUR 12185, Nuclear Science and Technology, Commission of the European Communities.

Johnk, C. T. A, 1988, Engineering Electromagnetic Fields and Wover, 2nd ed., John Wiley, New York.

Kaviany, M., 1991, Principles of Heal Transfer in Porous Media, Springer-Verlag, New York.

Li, W., Ebadian, M. A., White, T. L., Grubb, R. G., 1993a, Heat Transfer Within a Radioactive Contaminated Concrete Slab Applying a Microwave Heating Technique, ASME Transactions, Joumal of Heas Transfer, vol. 115, p.42

Li, W., Ebadian, M. A. White, T. L., Grubb, R. G. and Foster, D., 1993b. "Effect of Steel Reinforcement on Heat and Mass Transfer in a Contaminated Porous Concrete," Heat Transfer in Porous Media, HTD-Vol. 240, pp. 1-10, 1993 National Heat Transfer Conference.

Neville, A. M., 1981, Properties of Concrete, 3rd ed., Pitman, Massachusetts.
We, C. K., Davic, H. T., Davis, E. A, and Gordon, J., 1985, Heat and Mase Transer in Water-Loden Sandstone: Microwave Heating, AIChE J., vol. 31, 5, p.842.

White, T. L., Grubb, R. G., Pugh, L. P., Foster, D., Jr. and Box, W. D., March 1992, Removal of Contaminated Concrete Surfaces by Microwave Heating - Phase I Result, Presented at the 18th American Nuclear Society Symposium on Waste Management, Waste Management 92, Tucson, Arizona.

Yasunaka, H., Shibamoto, M., and Sukagawa, T., 1987, Microwave Decontaminator for Concrete Surface Decontamination in JPDR, Proceedings of the Int Decommissioning Sympasium, p. 109.

\section{NOMENCLATURE}

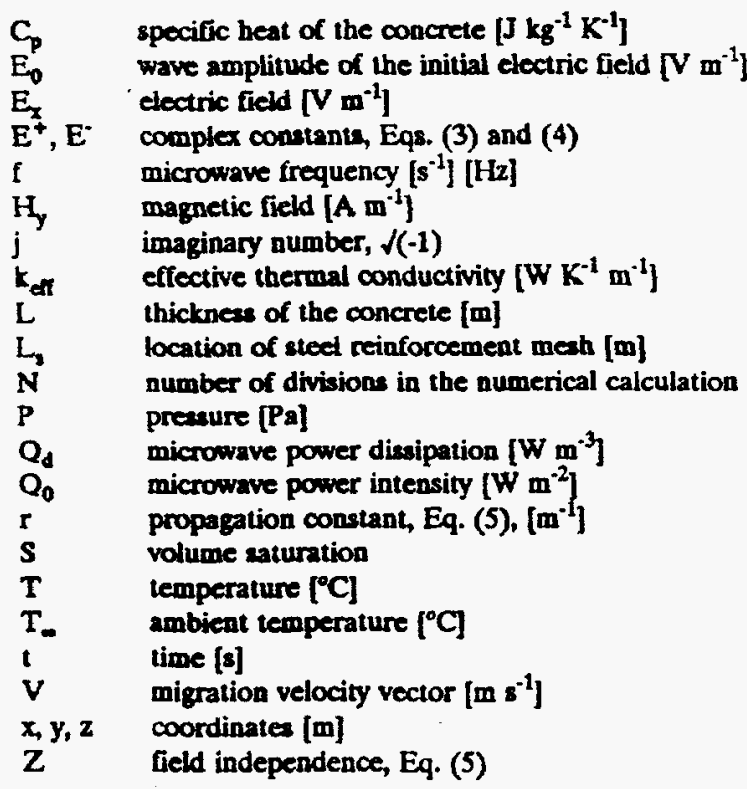

\section{Greek Symbols}

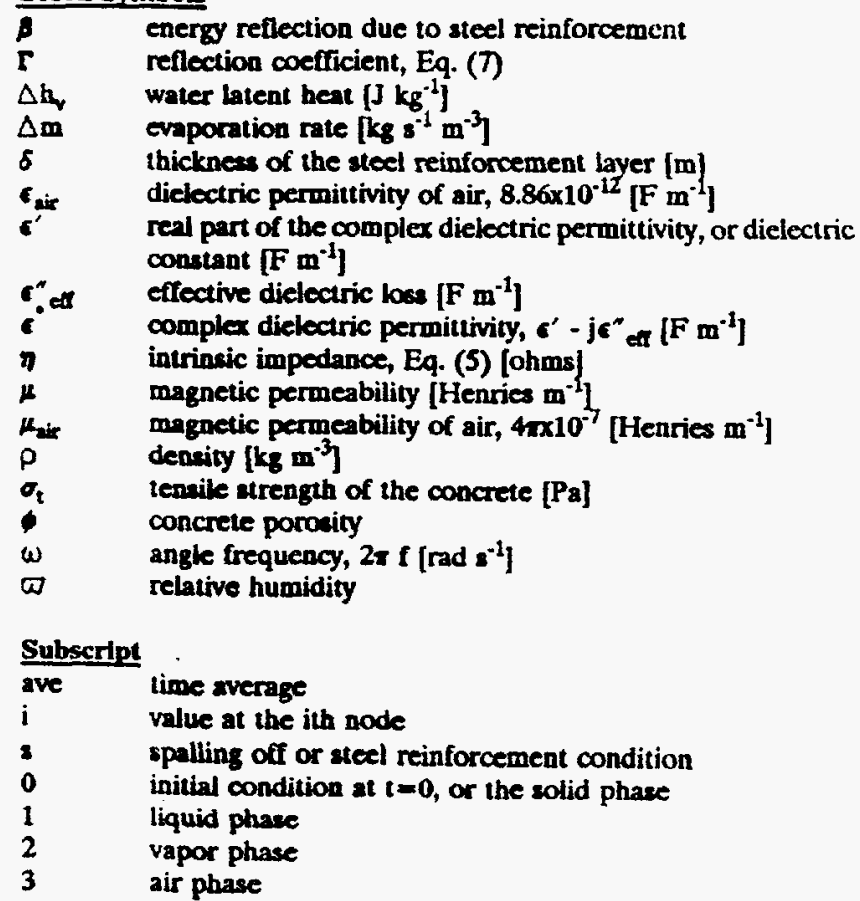

